\title{
Effects of granisetron and vagotomy on c-fos mRNA expression in the rat medulla oblongata as assessed by in situ hybridization
}

\author{
Toru Endo ${ }^{1}$, Masaru Minami ${ }^{1}$, Mitsuru Nakayasu${ }^{1}$, Masahiko Hirafuji ${ }^{1}$, Naoya Hamaue ${ }^{1}$, Naoki Omae ${ }^{1}$, \\ Youngnam $\mathrm{KANG}^{2}$ and Toshihiko IwANAGA ${ }^{3}$ \\ ${ }^{1}$ Department of Pharmacology, Faculty of Pharmaceutical Sciences, Health Sciences University of Hokkaido, Ishikari-Tobetsu 061-0293, \\ ${ }^{2}$ Department of Oral Physiology, Osaka University Graduate School of Dentistry, Suita 560-0781, and ${ }^{3}$ Laboratory of Histology and \\ Cytology, Graduate School of Medicine, Hokkaido University, Sapporo 060-8638, Japan
}

(Received 2 August 2004; and accepted 14 September 2004)

\begin{abstract}
Cancer chemotherapy-induced nausea and vomiting have been demonstrated to involve humoral as well as neuronal mechanisms. A leading role of serotonin (5-hydroxytryptamine, 5-HT) in these mechanisms is supported by inhibition of the emesis by $5-\mathrm{HT}_{3}$ receptor antagonists. We compared the effects of granisetron, a selective $5-\mathrm{HT}_{3}$ receptor antagonist, and vagotomy on c-fos mRNA expression in the nucleus of the solitary tract (NTS) and the area postrema (AP) of the rat caudal brainstem by means of in situ hybridization. The expression of c-fos mRNA in the NTS and AP was significantly elevated $2 \mathrm{~h}$ after cisplatin administration. The induction of c-fos expression by cisplatin in the NTS was significantly inhibited by pretreatment with granisetron. In contrast, the c-fos expression in the AP did not differ between the cisplatin group and the granisetron-treated cisplatin group. The degree of the induction of c-fos mRNA expression in both the AP and NTS was similar between the vagotomy and sham operation groups. Our results suggest that the expression of c-fos mRNA in the NTS may be specifically controlled by $5-\mathrm{HT}_{3}$ receptors and that nonspecific humoral factors, such as modulation of transcriptional activity, play an important role in c-fos expression in the AP after vagotomy.
\end{abstract}

Neuronal sites and signal substances involved in cancer chemotherapy-induced nausea and vomiting have been identified neurochemically (20). Serotonin type 3 receptor $\left(5-\mathrm{HT}_{3}\right.$ receptor) antagonists protect against emesis in experimental animal models as well as in cisplatin-treated patients with cancer (35). Autoradiographic studies of 5-HT in the central nervous system showed that binding sites with the strongest affinity for $5-\mathrm{HT}_{3}$ receptors are located in the nucleus of the solitary tract (NTS) and the area

Correspondence to: Dr. Toru Endo, Institute of Medical Science and Medical and Dental Clinic, Health Sciences University of Hokkaido, 2-5 Ainosato Kita-ku, Sapporo 002-8072, Hokkaido, Japan

Tel: +81-11-778-7575, Fax: +81-11-770-5034

E-mail: toruendo@hoku-iryo-u.ac.jp postrema (AP) of the caudal brainstem (33).

However, considerable evidence supports the hypothesis that cytotoxic drug-induced emesis is mediated by local 5-HT release in the intestinal wall (4, $14,15,27,28)$. 5-HT has a potent depolarizing action on the vagal afferent nerve $(18,34)$. It has been proposed that anticancer drugs cause 5-HT release from enterochromaffin (EC) cells to activate the $5-\mathrm{HT}_{3}$ receptors on the afferent vagal nerve fibers (1, 26). These afferent fibers may project to the dorsal vagal complex, which also expresses $5-\mathrm{HT}_{3}$ receptors on its central terminals $(20,33)$. The vomiting center receives input from the afferent vagal fibers to evoke an emetic reflex $(1,20)$. The vagus is the major nerve involved in the detection of emetic stimuli, and the abdominal vagus contains approximately $80-90 \%$ of the afferent fibers (3). Electrical 
stimulation of the abdominal vagal afferents is capable of inducing emesis (26), and abdominal vagotomy suppresses cisplatin-induced emesis $(12,17,40)$. Recent evidence supports the notion that $5-\mathrm{HT}_{3}$ receptor blockade at the level of the peripheral terminals of the vagal afferent fibers protects experimental animals and cancer patients from cisplatininduced emesis (2).

c-fos was proved to be a useful marker of neuronal activation because its expression is rapidly and intensely induced by such activation (31). c-fos expression as evaluated by in situ hybridization and immunohistochemistry is now widely used to map brain regions activated by various types of stimuli, including drugs $(21,32,36,39)$.

The existence of an integrative site that generates vomiting responses is still open to debate $(5,19$, 25). Therefore, we compared the expression patterns of c-fos mRNA in the dorsal vagal complex, NTS and AP of rats after treatment with cisplatin alone or with cisplatin plus granisetron, a selective $5-\mathrm{HT}_{3}$ receptor antagonist, by means of in situ hybridization. We also examined the effect of vagotomy on the c-fos mRNA expression.

\section{MATERIALS AND METHODS}

Animals. Male rats (weighing 180-300 g) were housed in groups of 3 or 4 animals in a temperature-controlled room $\left(23 \pm 1^{\circ} \mathrm{C}\right)$ with a 12-h light/ dark cycle (lights on from 8:00-20:00). Food and water were provided ad libitum. The rats were given a single dose of saline vehicle or cisplatin $(10 \mathrm{mg} / \mathrm{kg})$ intraperitoneally. Saline or granisetron $(1 \mathrm{mg} / \mathrm{kg}$ i. p.; SmithKline Beecham, Tokyo, Japan) was administered $10 \mathrm{~min}$ before the injection of cisplatin. Rats given cisplatin do not vomit, but display a characteristic behavior, namely eating of non-nutritive substances such as kaolin. This behavior is known as pica and is useful for the evaluation of emesis (24, 38).

Dissection of abdominal vagus nerve. Six rats received bilateral abdominal vagus nerve lesions 4 days before cisplatin administration. The other animals underwent sham operations. To create abdominal vagus nerve lesions, animals were deeply anesthetized with ketamine $(10 \mathrm{mg} / \mathrm{kg}$ i. p.). Under aseptic conditions, a bilateral (anterior and posterior nerves) vagal nerve excision was performed as described by Mackay and Andrews (22). The incisions were sutured and the animals were given penicillin. Postoperative recovery was uneventful in all tested rats.

In situ hybridization. After the rats were sacrificed with an overdose of ketamine, the brains were quickly removed and frozen at $-80^{\circ} \mathrm{C}$. Sections $(16$ $\mu \mathrm{m}$ thick) of the caudal medulla oblongata, including the dorsal vagal complex, were cut in a cryostat and placed on glass slides. The tissue sections were fixed with paraformaldehyde (4\%) for $15 \mathrm{~min}$ and were acetylated for $10 \mathrm{~min}$ with acetic anhydride $(0.25 \%)$ in $0.1 \mathrm{M}$ triethanolamine- $\mathrm{HCl}(\mathrm{pH} 8.0)$.

Two non-overlapping antisense oligonucleotides were used for in situ hybridization. They were complementary to nucleotide residues 601-645 and 1001-1045 of rat c-fos mRNA (database accession no. X06769). Prehybridization was performed in a hybridization buffer containing $50 \%$ formamide, 0.1 $\mathrm{M}$ Tris- $\mathrm{HCl}$ buffer (pH 8.0), $0.6 \mathrm{M} \mathrm{NaCl}, 1 \mathrm{mM}$ EDTA, $10 \%(\mathrm{w} / \mathrm{v})$ dextran sulfate (Sigma, St. Louis, MO, USA), $4 \times$ saline sodium citrate $(\mathrm{SSC})(1 \times$ $\mathrm{SSC}=150 \mathrm{mM} \mathrm{NaCl}$ and $15 \mathrm{mM}$ trisodium citrate), $0.25 \%$ sodium dodecyl sulfate, Denhardt's solution ( $0.02 \%$ bovine serum albumin, $0.02 \%$ Ficoll, $0.02 \%$ polyvinylpyrrolidone, Sigma), and $200 \mu \mathrm{g} / \mathrm{ml}$ tRNA.

The synthesized oligonucleotides were labeled with $\left[{ }^{35} \mathrm{~S}\right]$-dATP $(10,000 \mathrm{cpm} / \mu \mathrm{l})\left(\mathrm{NEN}^{\mathrm{TM}}\right.$; Life Science Products Inc., Boston, USA) using terminal deoxynucleotidyltransferase (Promega, WI, USA). Incubation in hybridization buffer was done at $42^{\circ} \mathrm{C}$ for $10 \mathrm{~h}$. The sections were washed at room temperature for $30 \mathrm{~min}$ in $2 \times \mathrm{SSC}$ and twice at $55^{\circ} \mathrm{C}$ for $40 \mathrm{~min}$ each in $0.1 \times \mathrm{SSC}$. The sections were exposed to X-ray films (Hyperfilm ${ }^{\mathrm{TM}}-\beta$ max; Amersham, Buckinghamshire, UK) for 1 week and to autoradiographic emulsion (Type NTB2; Kodak, NY, USA) for 2 months. The specificity of hybridization was confirmed by observing consistent labeling using two non-overlapping antisense probes as well as by the disappearance of the signals when an excess dose of cold probes was added to the hybridization fluid (data not shown).

Statistical analysis. For quantitative analysis of $\mathrm{X}$-ray films, densitometry was performed with a National Institutes of Health image analyzer. The results are expressed as \% change as compared with the control group. The numbers of cells expressing c-fos mRNA were quantified by counting heavily labeled cells with a light microscope (DMIRB; Leica, Tokyo, Japan) under dark-field illumination. The size of the tissue area surveyed in each rat was about $0.03 \mathrm{~mm}^{2}$. Data are expressed as means $\pm \mathrm{SE}$. The significance of differences between 2 groups 
was assessed with the F-test followed by the Student's t-test. One-way analysis of variance (ANOVA) with Dunnett's multiple comparison procedure was used to compare 3 or more groups (control, granisetron-treated, and vagotomy groups) (41). A $p$ value less than 0.05 was regarded as indicating statistical significance.

\section{RESULTS}

Time course of induction of c-fos mRNA expression by cisplatin

In situ hybridization analysis showed that cisplatin administration induced selective and intense expression of c-fos mRNA in the medulla oblongata $2-3 \mathrm{~h}$ after the treatment (Fig. 1). Under the light microscope, dark- and light-field images of hybridized sections showed c-fos mRNA-expressing cells in the AP and NTS after cisplatin administration (Fig. 2a, b). Heavy labeling was found both in small cells clustered in the AP and in large neurons dispersed in the NTS. Fig. 3 shows the time-course of the ex- pression of c-fos mRNA in the NTS (as determined by the densitometric analysis of X-ray films) 1 to 6 $\mathrm{h}$ after cisplatin administration. The expression of c-fos mRNA in the NTS 2 to $6 \mathrm{~h}$ after cisplatin administration was significantly higher than the control
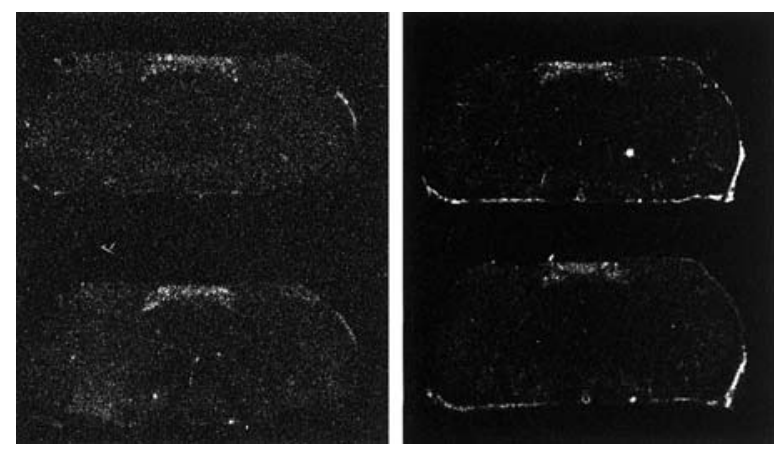

Fig. $1 X$ ray images showing in situ hybridization analysis of the expression of c-fos mRNA in the dorsal surface of the medulla oblongata in two rats. The expression sites correspond to the nucleus of the solitary tract and the area postrema.
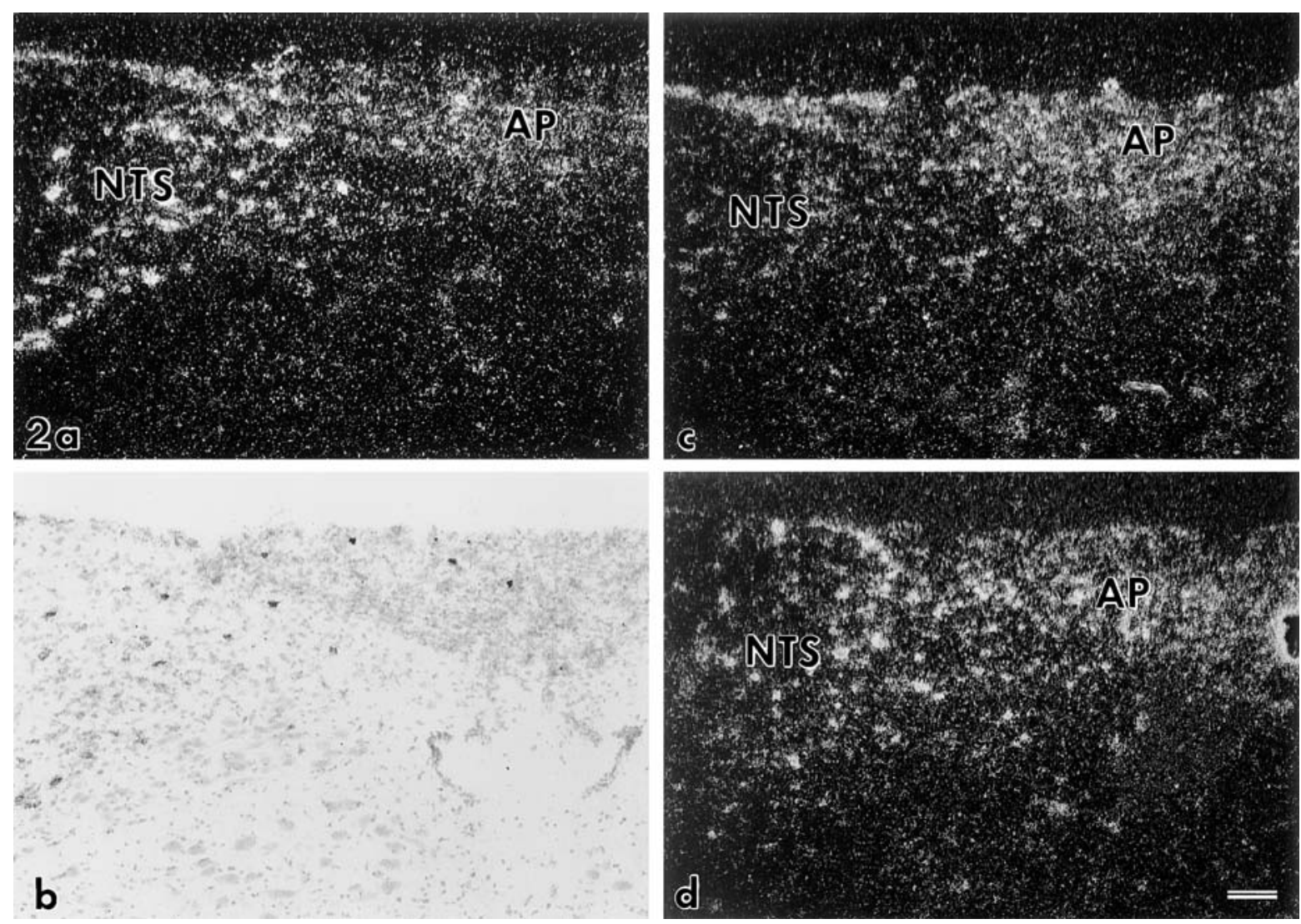

Fig. 2 Expression of c-fos mRNA induced by cisplatin in the rat medulla oblongata (2a, $2 \mathrm{~b})$ and the effect of granisetron (2c) or vagotomy $(2 \mathrm{~d})$. The medulla oblongata was obtained $2 \mathrm{~h}$ after cisplatin administration. Fig. $2 \mathrm{a}$ and $2 \mathrm{~b}$ are dark and bright field images of the same section. AP: area postrema, NTS: nucleus of the solitary tract 


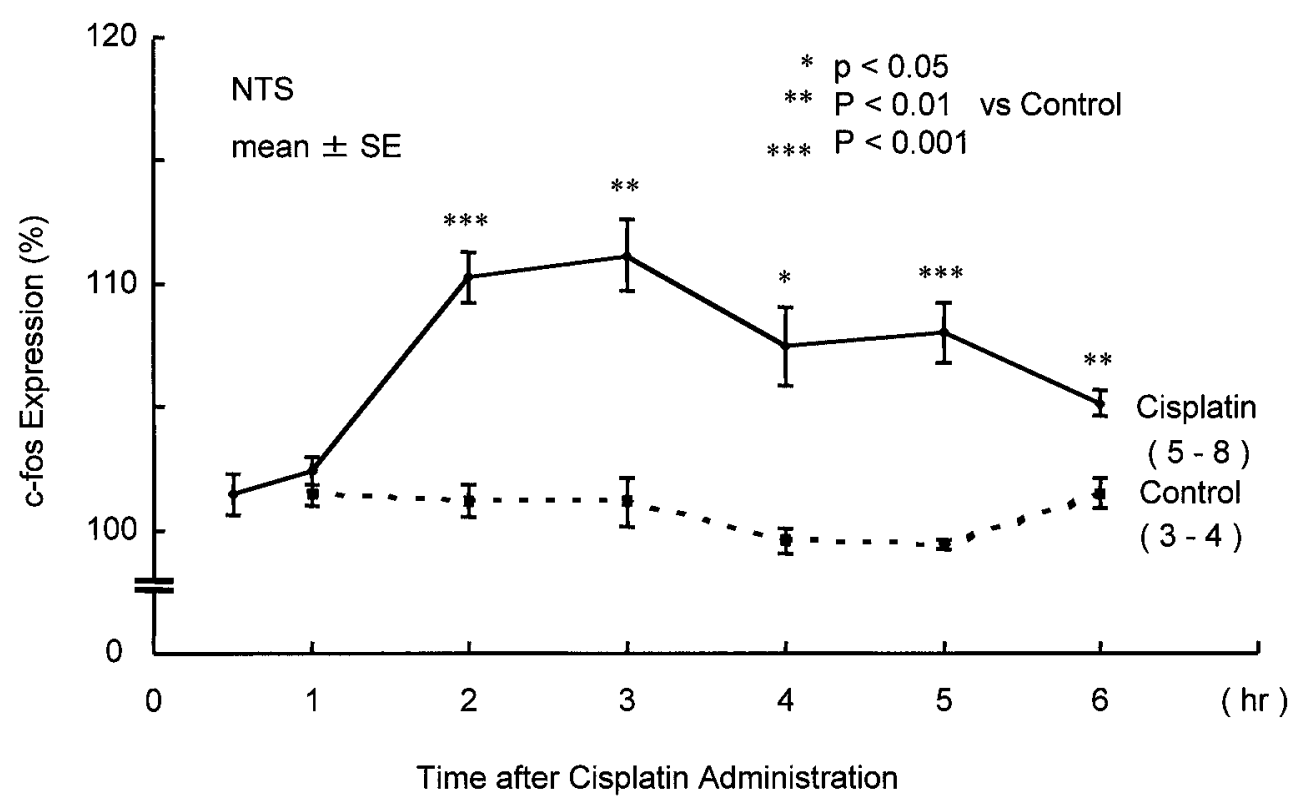

Fig. 3 Time course of the induction of c-fos expression by cisplatin in the nucleus of the solitary tract (NTS) quantitated by densitometry.

value. The c-fos expression peaked at $2-3 \mathrm{~h}$ after the administration of cisplatin. The increased c-fos expression was maintained up to $6 \mathrm{~h}$ after administration, but the expression level at $6 \mathrm{~h}$ was significantly lower than that at $2 \mathrm{~h}$ after treatment. The AP showed a similar pattern of c-fos mRNA expression to the NTS (data not shown).

Effect of granisetron, a selective 5-HT $T_{3}$ receptor antagonist, on the induction of c-fos expression by cisplatin

We examined the effects of granisetron, a selective $5-\mathrm{HT}_{3}$ receptor antagonist, on c-fos mRNA expression in the AP and NTS $2 \mathrm{~h}$ after the administration of cisplatin. Fig. 2c shows c-fos mRNA expression in the medulla oblongata after treatment with cisplatin plus granisetron. The c-fos mRNA expression in the AP of rats receiving granisetron before cisplatin was similar to that of the cisplatin control, while in the NTS there were few intensely labeled cells. Densitometric analysis confirmed that c-fos mRNA expression in the NTS was significantly inhibited by granisetron (Fig. 4).

Effect of vagotomy on the induction of c-fos expression by cisplatin

When the effects of vagotomy on c-Fos induction in the medulla oblongata were examined $2 \mathrm{~h}$ after the administration of cisplatin, there was no appreciable difference from the sham operation group in
8 of 12 rats. The remaining rats showed a slight trend toward c-fos induction. Fig. 2a and d show the dark-field images of c-fos mRNA expression in the AP and NTS regions in the cisplatin group (Fig. 2a) and the vagotomy plus cisplatin group (Fig. 2d), respectively. Comparison of the two groups revealed no significant effect of vagotomy on c-fos mRNA expression in the AP or NTS.

\section{DISCUSSION}

Here we studied on the c-fos induction in the brain stem of rats given cisplatin to understand the involvement of the medulla oblongata in cisplatin-induced emesis, since c-fos protein plays a role in nuclear events (transcription) associated with signal transduction processes in a manner analogous to immediate-early genes (29). Our study showed that pretreatment with the $5-\mathrm{HT}_{3}$ receptor antagonist granisetron significantly inhibited cisplatin-induced c-fos mRNA expression in the NTS of the medulla oblongata. Abdominal afferent vagal nerves are thought to have direct input to the dorsal nuclei of vagal nerve fibers as well as the NTS and AP (20, 33). Suppression of the cisplatin-induced c-fos expression by granisetron probably may involve two mechanisms. The first is the reduced release of 5-HT from enterochromaffin cells, which stimulates abdominal afferent vagal fibers distributed in the intestinal wall. The second mechanism is the inhibited 


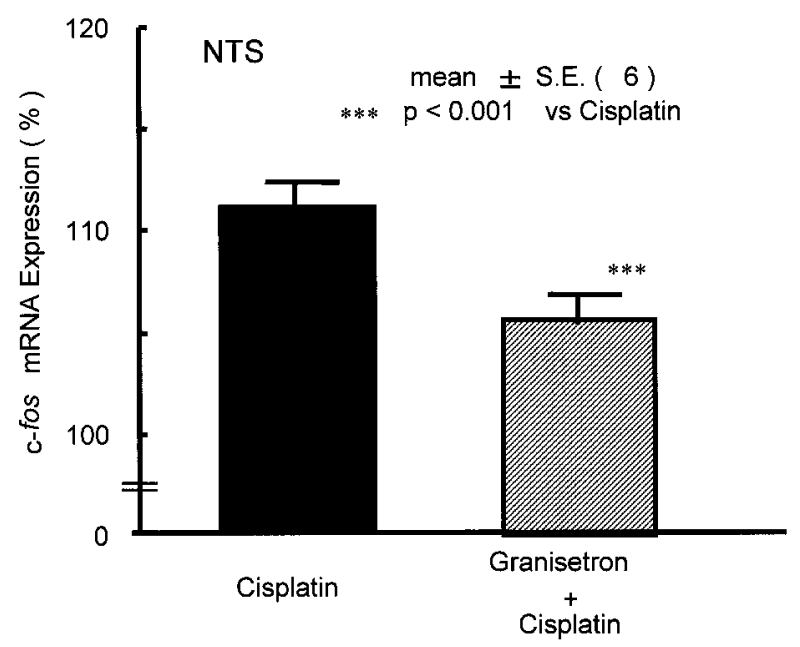

Fig. 4 Effect of granisetron on the induction of c-fos expression by cisplatin in the rat the nucleus of solitary tract (NTS) quantitated by densitometory.

input to the NTS, resulting from the blockade of $5-\mathrm{HT}_{3}$ receptors at peripheral terminals of the abdominal afferent vagal fibers. The granisetron-induced blockade of the vomiting signal input to NTS via $5-\mathrm{HT}_{3}$ receptors suggests that input from the AP to the NTS is blocked. However, cisplatin-induced c-fos mRNA expression in the AP was not affected by pretreatment with granisetron. Because AP also functions as a chemoreceptor trigger zone, humoral factors probably play an important role in the induction of c-fos mRNA expression by cisplatin in the AP. Pretreatment with granisetron had no discernible effect on c-fos mRNA expression induced by circulatory or systemic effects. It also appeared that $5-\mathrm{HT}_{3}$ receptors were not densely distributed in the AP. Input from the AP to the NTS, however, was also apparently inhibited by granisetron. These findings suggest that granisetron blocks input to the NTS in addition to acting on 5- $\mathrm{HT}_{3}$ receptors on the peripheral terminals of the abdominal afferent vagal fibers $(15,16)$.

One of the most important methodological considerations for immunohistochemical analyses of c-fos is the time course of c-fos elevation and decay (10). After a seizure, the elevated c-fos levels in neurons generally decrease more slowly than those in cell culture systems (30). Neuronal c-fos levels after a seizure have been reported to return to nearly baseline values within $24 \mathrm{~h}$, although the onset latency and time of maximal c-fos accumulation in neurons after seizures are region-dependent in the brain (9). In our study, however, the cisplatin-induced c-fos mRNA expression in the NTS and AP was highest 2 and $3 \mathrm{~h}$ after cisplatin administration and returned to the baseline value $6 \mathrm{~h}$ later. Consistent with the pattern of c-fos mRNA expression seen in the present study, cisplatin-induced vomiting in the ferret starts $2 \mathrm{~h}$ after administration and continues for $6 \mathrm{~h}$ (11). In rats, which show pica, a type of emesis $(23,37)$, abdominal afferent vagal nerve activity increases $2 \mathrm{~h}$ after cisplatin treatment (13).

Miller et al. (25) clearly demonstrated that emetic drugs excite neurons in the AP. After removal of the $\mathrm{AP}$, however, vomiting induced by $5-\mathrm{HT}_{3}$ receptor agonists or by electrical stimulation of the abdominal vagus nerve cannot be inhibited (25). These findings suggest that neuronal excitation in the AP does not play an essential role in the vomiting caused by 5 -HT-mediated abdominal afferent vagal nerve stimulation and that activation of the AP evokes emesis via projections to the adjacent NTS. Vagotomy decreases the excitation threshold in the AP. Excitation is therefore transmitted to the NTS, but is too weak to induce emesis. The induction of c-fos at this time apparently depends on transcription-related differences after vagotomy. c-fos expression can be induced rapidly and transiently by a great variety of agents, such as 5-HT, acetylcholine, and humoral factors (8). Neurons in regions of the medulla oblongata, including the AP, are excited by gastrin, histamine, substance $\mathrm{P}$, and enkephalin as well as 5-HT $(6,7)$. Cisplatin may have directly stimulated the release of these neurotransmitters in the AP or NTS. Alternatively, cisplatin may have facilitated neurotransmitter release in the intestine; these neurotransmitters then systemically reached the chemoreceptor trigger zone and induced c-fos expression in the AP.

In both the AP and NTS, c-fos mRNA expression was essentially unchanged between the cisplatin group and the cisplatin group receiving vagotomy. We previously reported that cisplatin-induced vomiting is inhibited in $80 \%$ of ferrets undergoing vagotomy $(12,26) .5-$-HT levels in the AP and NTS regions of cisplatin-administered animals were significantly increased as compared with those of saline-administered control animals. The 5-HT level of animals pretreated with $5-\mathrm{HT}_{3}$ receptor antagonist or vagotomy was significantly lower than that of the cisplatin-treated animals (26). Taken together, the findings of this previous study by us suggested that cytotoxic drugs induce emesis mainly through actions on the gastrointestinal tract. We have reported that vagotomy inhibited vomiting (12), but the present study did not find c-fos induction, implying that the relationship between c-fos induction and emetic 
behavior is not direct. These results also suggest that abdominal vagotomy is effective for the inhibition of emetic stimuli which release 5-HT from the gut and stimulate the vagal afferent nerves. On the other hand, abdominal vagotomy may be ineffective for emesis in which humoral agents excite the AP.

\section{REFERENCES}

1. Andrews PLR, Rapeport WG and Sanger GJ (1988) Neuropharmacology of emesis induced by anti-cancer therapy. Trends Pharmacol Sci 9, 334-341.

2. Andrews PLR, Davis CJ, Bingham S, Davidson HIM, Hawthorn J and Maskell L (1990) The abdominal visceral innervation and the emetic reflex: pathways, pharmacology and plasticity. Can J Physiol Pharmacol 68, 325-345.

3. Andrews PLR (1992) Physiology of nausea and vomiting. $\mathrm{Br}$ $J$ Anaesth 69, 2s-19s.

4. Andrews PLR and Davis CJ (1995) The physiology of emesis induced by anti-cancer therapy. In: Serotonin and the Scientific Basis of Antiemetic Therapy (Reynolds DJM, Andrews PLR and Davis CJ, eds), pp 25-49, Oxford Clinical Communications, Oxford.

5. Barnes JH (1984) The physiology and pharmacology of emesis. Mol Aspects Med 7, 397-508.

6. Borison HL, Borison R and McCarthy LE (1984) Role of the area postrema in vomiting and related functions. Fed Proc 43, 2955-2958.

7. Carpenter DO, Briggs DB and Strominger N (1983) Responses of neurons of canine area postrema to neurotransmitters and peptides. Cell Mol Neurobiol 3, 113-126.

8. Curran T, Gordon MB, Rubino KL and Sambucetti LC (1987) Isolation and characterization of the c-Fos (rat) cDNA and analysis of post-translational modification in vitro. Oncogene 2, 79-84.

9. Dragunow M and Robertson HA (1987) Generalized seizures induce c-Fos proteins in mammalian neurons. Neurosci Lett 82, 157-161.

10. Dragunow M and Faull R (1989) The use of c-Fos as a metabolic marker in neuronal pathway tracing. J Neurosci Methods 29, 261-265.

11. Endo T, Minami M, Monma Y, Yoshioka M, Saito H, Kinami J, Toshimitsu Y and Parvez H (1990) Effect of GR38032F on cisplatin- and cyclophosphamide-induced emesis in the ferret. Biogenic Amines 7, 525-533.

12. Endo T, Minami M, Monma Y, Yoshioka M, Saito $H$ and Parves H (1992) Vagotomy and ondansetron (5-HT 3 antagonist) inhibited the increase of serotonin concentration induced by cytotoxic drugs in the area postrema of ferrets. Biogenic Amines 9, 163-175.

13. Endo T, Nemoto $M$, Minami M, Yoshioka $M$, Saito $H$ and Parvez H (1995) Changes in the afferent abdominal vagal nerve activity induced by cisplatin and copper sulfate in the ferret. Biogenic Amines 11, 399-407.

14. Endo T, Ogawa T, Hamaue N, Akita K, Hirafuji M, Minami $\mathrm{M}$ and Blower PR (1998) Granisetron, a 5- $\mathrm{HT}_{3}$ receptor antagonist, inhibited cisplatin-induced 5-hydroxytryptamine release in the isolated ileum of ferrets. Res Comm Mol Pathol Pharmacol 100, 243-253.

15. Endo T, Minami M, Kitamura N, Teramoto Y, Ogawa T, Nemoto M, Hamaue N, Hirafuji M, Yasuda E and Blower PR (1990) Effects of various 5- $\mathrm{HT}_{3}$ receptor antagonists, granisetron, ondansetron, ramosetron and azasetron on sero- tonin release from the ferret isolated-ileum. Res Comm Mol Pathol Pharmacol 104, 145-155.

16. Endo T, Minami M, Hirafuji M, Ogawa T, Akita K, Nemoto M, Saito H, Yoshioka M and Parvez SH (2000) Neurochemistry and neuropharmacology of emesis - the role of serotonin. Toxicology 153, 189-201.

17. Hawthorn J, Ostler KJ and Andrews PLR (1988) The role of the abdominal visceral innervation and 5-hydroxytryptamine M-receptors in vomiting induced by the cytotoxic drugs cyclophosphamide and cisplatin in the ferret. J Exp Physiol 73, $7-21$.

18. Ireland SJ and Tyers MB (1987) Pharmacological characterization of 5-hydroxy-tryptamine-induced depolarization of the rat isolated vagus nerve. Br J Pharmacol 90, 229-238.

19. Koga T, Qu R and Fukuda H (1998) The central pattern generator for vomiting may exist in the reticular area dorsomedial to the retrofacial nucleus in dogs. Exp Brain Res 118, 139-147.

20. Leslie RA, Reynolds DJM, Andrews PLR, Grahame-Smith DG, Davis CJ and Harvey JM (1990) Evidence for presynaptic $5-\mathrm{HT}_{3}$ recognition sites on vagal afferent terminals in the brainstem of the ferret. Neuroscience 38, 667-673.

21. Luo L and Jackson IMD (1999) Advantage of double labeled in situ hybridization for detecting the effects of glucocorticoids on the mRNAs of protooncogenes and neural peptides (TRH) in cultured hypothalamic neurons. Brain Res Proto 4, 201-208.

22. Mackay TW and Andrews PLR (1983) A comparative study of the vagal innervation of the stomach in man and the ferret. J Anat 136, 449-481.

23. McCaffrey RJ (1985) Appropriateness of kaolin consumption as an index of motion sickness in the rat. Physiol Behav 35, 151-156.

24. Mitchell D, Krusemark ML and Hafner D (1977) Pica: a species relevant behavioral assay of motion sickness in the rat. Physiol Behav 18, 125-130.

25. Miller AD, Nonaka S and Jakus J (1994) Brain areas essential of non essential for emesis. Brain Res 647, 255-264.

26. Minami M, Endo T, Nemoto M, Hamaue N, Hirafuji M, Monma Y, Yajima T, Yoshioka M. and Saito H (1995) How to toxic emetic stimuli cause serotonin release in the gut and the brain? In: Serotonin and the Scientific Basis of Antiemetic Therapy (Reynolds DJM, Andrews PLR and Davis CJ, eds), pp 68-76, Oxford Clinical Communications, Oxford.

27. Minami M, Ogawa T, Endo T, Hamaue N, Hirafuji M, Yoshioka M, Blower PR. and Andrews PLR (1997) Cyclophophamide increases 5-hydroxytryptamine release from the isolated ileum of the rat. Res Comm Mol Pathol Pharmacol 97, 1324.

28. Minami M, Kohno Y, Endo T, Nemoto M, Ogawa T, Ihira E, Hamaue N and Hirafuji M (1999) Differential effects of talipexole and bromocriptine on serotonin release from rat intestinal tissues-an in vitro study of the emetic response of antiparkinsonian dopamine agonists. Res Comm Mol Pathol Pharmacol 104, 3-12.

29. Morgan JI and Curran T (1986) Role of iron flux in the control of c-Fos expresion. Nature 322, 552-555.

30. Morgan JI, Cohen DR, Hempstead JL and Curran T (1987) Mapping patterns of c-Fos expression in the central nervous system after seizure. Science 237, 192-197.

31. Morgan JI and Curran T (1991) Stimulus-transcription coupling in the nervous system: involvement of the inducible proto-oncogenes fos and jun. Ann Rev Neurosci 14, 421-451.

32. Mowa CN and Iwanaga T (2000) Differential distribution of 
oestrogen receptor-alpha and -beta mRNAs in the female reproductive organ of rats as revealed by in situ hybridization. $J$ Endocrinol 165, 59-66.

33. Pratt GD, Bowery NG, Kilpatrick GJ, Leslie RA, Barnes NM, Naylor RJ, Jones BJ, Nelson DR, Palacios JM, Slater P and Reynolds DJM (1990) Consensus meeting agrees distribution $5-\mathrm{HT}_{3}$ receptors in mammalian hind-brain. Trends Pharmacol Sci 11, 135-137.

34. Round A and Wallis DI (1986) The depolarizing action of 5 -hydroxytryptamine on rabbit vagal afferent and sympathetic neurons in vitro and its selective blockade by ICS205-930. Br J Pharmacol 88, 485-494.

35. Sanger GJ (1990) New antiemetic drugs. Can J Physiol Pharmacol 68, 314-324.

36. Semba J, Sakai MW, Suhara T and Akanuma N (1999) Differential effects of acute and chronic treatment with typical and atypical neuroleptics on c-Fos mRNA expression in rat forebrain regions using non-radioactive in situ hybridization. Neurochem Intern 34, 269-277.

37. Snowdon C T and Sanderson BA (1974) Lead pica produced in rats. Science 183, 92-94.

38. Takeda N, Hasegawa S, Morita M and Matsunaga T (1993) Pica in rats is analogous to emesis: an animal model in emesis research. Pharmacol Biochem Behav 45, 817-821.

39. Tanaka J, Murate M, Wang CZ, Seino S and Iwanaga T (1996) Cellular distribution of the P2X4 ATP receptor mRNA in the brain and non-neuronal organs of rats. Arch Histol Cytol 59, 485-490.

40. Torii Y, Saito H and Matsuki N (1990) Selective blockade of cytotoxic drug-induced emesis by $5-\mathrm{HT}_{3}$ receptor antagonists in Suncus murinus. Jpn J Pharmac 55, 107-113.

41. Wallenstein SC, Zucker L and Freiss JL (1980) Some statistical methods useful in circulation research, Cir Res 47, 1-9. 